\title{
Evaluation of the Efficiency of Supinator Tendon Transfer to Wrist Extensor in Brachial Plexus Injuries at C7-T1, A Case Study Based on OpenSIM Modelling Approach
}

mohammad Karimi ( $\nabla$ mohammad.karimi.bioengineering@gmail.com )

Shiraz University of Medical Sciences https://orcid.org/0000-0001-6162-8131

Hamid Namazi

Shiraz University of Medical Sciences

Research article

Keywords: Wrist extensor paralysis, tendon transfer, supinator, modeling, OpenSim

Posted Date: November 1st, 2021

DOl: https://doi.org/10.21203/rs.3.rs-627453/v1

License: (c) (i) This work is licensed under a Creative Commons Attribution 4.0 International License.

Read Full License 


\section{Abstract}

\section{Background}

The incidence of brachial plexus injuries (BPI) is increasing due to improvement in transportation technology. Those with BPI have upper limb performance limitation depends on the type of injury. Various surgical treatments have been used in this group of the subjects to restore their performance. The aim of this study was to evaluate the efficiency of supinator transferred to wrist extensors in those with lesion level at C7-T1 based on OpenSim modelling approach.

\section{Method}

The motions of the upper limb during vertical reaching, transverse reaching and wrist motion of a normal subject were achieved by use of motion analysis system. The ranges of motion of the upper limb joints were evaluated by inverse kinematic. OpenSim software was used to determine the muscles forces during aforementioned tasks. Tendon of supinator was transferred to extensors in modified models of OpenSim. Forward dynamic approach was used to determine the range of motion in tendon transferred condition.

Results

The range of wrist motion in normal condition (extensors intake) were 85, 103 and 140 degrees for the first task (transverse reaching), the second task (vertical reaching) and the third task (only flexion/extension of wrist), respectively. Although the force of supinator was significantly less than that of wrist extensors, the pattern of its force is the same as wrist extensors.

\section{Introduction}

Brachial plexus (BP) is the network of nerves responsible to innervate the shoulder, arm and hand. Brachial plexus injuries (BPI) occur mostly when the nerves are stretched, compressed or disconnected from spinal cord [1-4]. The BPI can be classified into simple injuries and severe injuries, which are the results of sport and motor traffic accidents, respectively. The incidence of BPI has rapidly increased due to improvement and advancement in transportation technology $[1,5]$.

Depends on the type and severity of injuries, those with BPI miss their abilities to do their daily activities and may have weakness or paralysis of hand, arm and shoulder musculatures [6, 7]. Various methods of treatment have been used to restore the abilities of the subjects including conservative treatment and surgery [8-10]. Although those with BPI achieve reasonable function with use of assistive devices, robotic rehabilitation and physical therapy, most of them require especial surgeries to enhance their upper limb function [6].

Depends on the type of injury, a variety of surgical treatment can be used to improve the functional outcome $[1,11]$. The surgical treatment used for BPI can be divided into primary and secondary treatment $[1,2,6]$. Neurolysis, nerve grafting and neurotisation are some of the primary surgical treatments. If there 
is no sign of neurological regeneration or no possibility of neurological recovery with any functional improvement, secondary surgical procedure will be done [2].

The secondary surgical treatments for BPI include arthrodesis, nerve graft, nerve transfer and tendon transfer $[2,11]$. Depends of type of injury various tendon transfers can be used for this group of subjects. Those with lesion at levels C7-T1 have full range of motion in elbow and shoulder joints. However, the strength of the muscles surrounding these joints markedly reduces compared to normal side $[1,6,10]$. It has been reported that elbow flexion and extension strength decreased by $39 \%$ and $75 \%$, respectively. Active Wrist flexion and extension miss in those with lesion at C7-T1. Moreover when these patients extend their wrist, radial division occurs [6].

To restore the function of wrist joint extensors, tendon transfer may be used. There are not enough evidences regarding the tendon which can be transferred to wrist extensors to enhance the wrist function in these patients. The aim of this research was to investigate the efficiency of tendon of supinator transferred to wrist extensors in daily activities. The main hypothesis associated with this study was that tendon of supinator can be used to improve the wrist joint extension in the patients with BPI at C7-T1.

\section{Method}

A subject with age of 45 years, height of $1.7 \mathrm{~m}$ participated in this study. An ethical approval was obtained from Shiraz University of Medical Sciences, ethical committee. A consent form was signed by the subject before data collection.

A motion analysis system with 7 high speed cameras, was used to monitor the motions of the upper limb in doing various tasks. A Qualysis motion analysis system was used to monitor and to collect the motions. Some reflective markers were attached on hand (base of third MCP), wrist (radial and ulnar styloid process), medial and lateral elbow epicondyles, shoulder joint, acromioclavicular joint, Sternoclavicular joint, sternal notch and xyphoid process. The subject was asked to move some standard blocks in vertical and transverse directions. Moreover, he was asked to move his wrist from full flexion to full extension. A table with height equal to distance between ground to anterior superior iliac spine (ASIS) was used to do transverse reaching task. A cylindrical weight with mass, height and diameter equal to $0.25 \mathrm{~kg}, 5 \mathrm{~cm}$ and $5 \mathrm{~cm}$, respectively was used for this part of the research. The cylindrical weight was positioned approximately $15 \mathrm{~cm}$ apart from the main table. For vertical reaching task a small table with height of $20 \mathrm{~cm}$ was used. The subject was asked to move the block on top of the small table without considering the location and return it to the previous position.

In the third part of the research the subject was asked to move the wrist from full flexion to full extension. The data were recorded with frequency of $100 \mathrm{Hrz}$. The markers were labelled and exported as $3 \mathrm{~d}$ files to Mokka software. Mokka software was used to change the format of the data from $3 \mathrm{~d}$ to trc. OpenSim software was used to determine the range of motions of the joint and muscle forces of the upper limb and also to determine the efficiency of the tendon transfer $[12,13]$. 
Inverse kinematic was used to determine the range of motions of the joints during the mentioned tasks. The muscles force was determined by use of computer muscles control approach. Forward dynamic was used to determine the range of motions of the joints based on muscles force inputs [12]. It should be emphasized that forward dynamic approach was used for the following purposes.

1. To determine ROM of the joints based on normal model with active wrist extensors

2. To determine the ROM of the joints based on normal model with paralyzed wrist extensors

3. To determine the ROM of the joints based on the muscles inputs and modified model (paralyzed wrist extensors, flexors and supinator tendon transferred to extensors).

It should be noted that verification of the approach was done based on the outputs of forward dynamic of the normal model compared to ROM outputs obtained from inverse kinematic. It means that the muscle forces obtained from normal model was used to determine the range of motion of the joints in forward dynamic. The accuracy of the model and approach is based on the difference between the results of forward dynamic (output) and ROM of inverse kinematic (input).

The difference between ROM of inverse dynamic and forward dynamic was evaluated by two sample $t$ test to determine the feasibility of this approach. The difference between the outputs of the model (ROM) in tendon transferred condition with normal model was determined to evaluate the efficiency of tendon transferred. Figures 1 and 2 show the diagram of the procedure used in this study. Figure 3 shows the model used in this study.

\section{Results}

Table 1 shows the range of motions of the upper limb during doing different tasks. As was mentioned, those were obtained from motion analysis system (inverse kinematic). As can be seen from this table, the range of motion of wrist joint were 85, 103 and 140 degree for task 1 (transverse reaching), task 2 (vertical reaching) and task 3 (absolute wrist motion). Elbow joint moved 20 degrees, 40 and 0 degrees for task 1,2 and 3 , respectively.

The peaks of muscle force during doing the aforementioned tasks are shown in Table 2. As can be seen from this table, the peak of the force of extensor muscles varied between 38-94, 35-138 and 28-71 $\mathrm{N}$ for tasks 1, 2 and 3, respectively. The forces of supinator were $57 \mathrm{~N}$ for task $1,45 \mathrm{~N}$ for task 2 and $34 \mathrm{~N}$ for task 3. The force of pronator teres varied between $430 \mathrm{~N}$ and $716 \mathrm{~N}$. Figures 4 and 5 shows the pattern of wrist extensors, flexor, pronator and supinator for tasks 1, 2 and 3, respectively. 
Table 1

The range of motion of the upper limb joints while doing three different tasks

\begin{tabular}{|llll|}
\hline Motion (degree) & Task 1 & Task2 & Task3 \\
\hline Wrist flexion & 35 & 35 & 80 \\
\hline Wrist extension & 50 & 68 & 60 \\
\hline Range & 85 & 103 & 140 \\
\hline Wrist abduction & 20 & 7 & 0 \\
\hline Wrist adduction & 32 & 28 & 0 \\
\hline Range & 52 & 35 & 0 \\
\hline Wrist supination & 7 pronation & 16 pronation & 18 \\
\hline Wrist pronation & 23 pronation & 38 pronation & 0 \\
\hline Range & 16 & 22 & 18 \\
\hline Elbow flexion & 50 flexion & 69 flexion & 90 flexion \\
\hline Elbow extension & 30 flexion & 29 flexion & 90 flexion \\
\hline Range & 20 & 40 & 0 \\
\hline Shoulder flexion & 47 flexion & 61 flexion & 21 \\
\hline Shoulder extension & 20 flexion & 31 flexion & 21 \\
\hline Range & 27 & 30 & 0 \\
\hline Shoulder abduction & 20 & 73 & 50 abduction \\
\hline Shoulder adduction & 73 & 44 abduction & 50 abduction \\
\hline Range & 93 & 29 & 0 \\
\hline Shoulder internal rotation & 51 external rotation & 23.5 external rotation & 10 \\
\hline Shoulder external rotation & 65 & 52 & 10 \\
\hline Range & 14 & 28.5 & 0 \\
\hline
\end{tabular}

The ranges of motion of wrist joint, based on forward dynamic approach, were 81,55 and 113 for task 1 , 2 and 3 , respectively. The difference between the mean values of the outputs based on inverse dynamic and forward dynamic approaches were not significant ( $p$-value $>0.05)$. 
Table 2

Muscles forces while doing three different tasks

\begin{tabular}{|llll|}
\hline Muscles forces (N) & Task 1 & Task2 & Task3 \\
\hline Abductor policis longus & 100 & 25 & 87 \\
\hline Flexor policis longus & 140 & 114 & 77 \\
\hline Flexor policis brevis & 45 & 25 & 40 \\
\hline Extensor policis longus & 80 & 35 & 71 \\
\hline Extensor indicis proprius & 50 & 55 & 44 \\
\hline Extensor digiti minimi & 70 & 95 & 48 \\
\hline Extensor digitorum communis index & 37 & 50 & 31 \\
\hline Extensor digitorum communis & 80 & 122 & 66 \\
\hline Extensor digitorum communis ring & 94 & 138 & 70 \\
\hline Extensor digitorum communis longus & 38 & 53 & 28 \\
\hline FDPI & 150 & 120 & 30 \\
\hline FDSL & 150 & 47 & 28.8 \\
\hline FDSR & 65 & 106 & 68 \\
\hline Flexor digitorum superfisialise & 185 & 153 & 41 \\
\hline FDSI & 120 & 97 & 18 \\
\hline FDPI & 150 & 195 & 136 \\
\hline FDPR & 87 & 136 & 87 \\
\hline Flexor digitorum profundus & 150 & 140 & 44 \\
\hline Supinator & 57 & 145 & 34 \\
\hline Extensor carpi radialis longus & 311 & 153 & 231 \\
\hline Extensor carpi radialis brevis & 259 & 166 & 260 \\
\hline Extensor carpi ulnaris & 120 & 250 & 127 \\
\hline Extensor carpi radialis & 110 & 145 & 101 \\
\hline Flexor carpi ulnaris & 37 & 244 & 196 \\
\hline Palmaris longus & 19 & 16.5 \\
\hline Pronator teres & 280 & 241 \\
\hline Pronator quadratus & 30 & \\
\hline
\end{tabular}


Wrist joint moved by 138.6 degrees for task 1 . For the second task, it was 120 degrees compared to 138 degrees for the third task. The range of motions of wrist joint supination/pronation was $65.6,60$ and 63.7 degrees, respectively. Table 3 summarizes the ROM of the joints based on transfer tendon of supinator.

Table 3

The range of motion obtained from forward dynamic based on transferred tendon of supinator to extensor

\begin{tabular}{|llll|}
\hline Motion (degree) & Task 1 & Task2 & Task3 \\
\hline Wrist flexion & 63.6 & 90 & 63 \\
\hline Wrist extension & 75 & 30 & 75 \\
\hline Range & 138.6 & 120 & 138 \\
\hline Wrist abduction & 12 & 31 & 11.5 \\
\hline Wrist adduction & 0 & 32.5 & 22.7 \\
\hline Range & 12 & 63.5 & 34.2 \\
\hline Wrist supination & 35.6 & 15 & 33.7 \\
\hline Wrist pronation & 30 & 45 & 30 \\
\hline Range & 65.6 & 60 & 63.7 \\
\hline Elbow flexion & 137 flexion & 48 flexion & 95 flexion \\
\hline Elbow extension & 40 flexion & 36 flexion & 42.5 \\
\hline Range & 97 & 12 & 42.5 \\
\hline Shoulder flexion & 74 flexion & 52.6 flexion & 2.5 extension \\
\hline Shoulder extension & 43 flexion & 52.6 flexion & 28.9 extension \\
\hline Range & 31 & 0 & 26.4 \\
\hline Shoulder abduction & 72 abduction & 59 abduction & 23.4 abduction \\
\hline Shoulder adduction & 35 abduction & 58 abduction & 0 \\
\hline Range & 37 & 1 & 23.4 \\
\hline Shoulder internal rotation & 4.56 ext rot & 20.6 ext rot & 11 ext rot \\
\hline Shoulder external rotation & 20 & 29.6 & 15 \\
\hline Range & 15.04 & 9 & 4 \\
\hline
\end{tabular}

The p-values of the difference of the upper extremity joints are shown in Table 4. As can be seen from this table, there was no significant difference between the mean values of flexion/extension ROM of wrist joint between normal condition and paralyzed extensors with tendon transferred of supinator. 
Table 4

The range of motions of the joints in different conditions and $p$-values of the differences

\begin{tabular}{|c|c|c|c|c|c|c|c|}
\hline \multirow[t]{2}{*}{ Motion (degree) } & \multicolumn{3}{|c|}{ Normal condition (A) } & \multicolumn{3}{|c|}{ Supinator transfer (B) } & \multirow[t]{2}{*}{ Comparison A\&B } \\
\hline & $\begin{array}{l}\text { Task } \\
1\end{array}$ & Task2 & Task3 & $\begin{array}{l}\text { Task } \\
1\end{array}$ & Task2 & Task3 & \\
\hline $\begin{array}{l}\text { Wrist } \\
\text { Flexion/extension }\end{array}$ & 85 & 103 & 140 & 138.6 & 120 & 138 & 0.15 \\
\hline Wrist abd/add & 52 & 35 & 0 & 12 & 63.5 & 34.2 & 0.37 \\
\hline supination/pronation & 16 & 22 & 18 & 65.6 & 60 & 63.7 & 0.0 \\
\hline Elbow & 20 & 40 & 0 & 97 & 12 & 42.5 & 0.17 \\
\hline shoulder flex & 27 & 30 & 0 & 31 & 0 & 26.4 & 0.5 \\
\hline shoulder abd/add & 93 & 29 & 0 & 37 & 1 & 27.4 & 0.28 \\
\hline shoulder rotation & 14 & 28.5 & 0 & 15.04 & 9 & 4.2 & 0.31 \\
\hline
\end{tabular}

\section{Discussion}

Brachial plexus injuries (BPI) occur mostly due to traffic road accident. Various treatment approaches have been used in this group of the subjects to restore the performance of the upper limb musculatures depends on level of injury [10]. Those with BPI at C7-T1 miss their wrist flexion and extension. Tendon transfer is one of the secondary surgical procedures used for this group of the subjects. The aim of this study was to evaluate the efficiency of use of supinator transferred to wrist extensor to restore the wrist range of extension in daily activities.

The results of this study showed that the force of supinator can be used to restore the performance of extensor. There was no significant difference between the flexion/extension of wrist joint between the model outputs based on supinator transfer (extensors and flexors paralyzed) and normal model (extensor and flexors intake), Tables1, 3 and 4. Moreover, it does not influence the motion of other joints. However, as can be seen from Table 1, the wrist joint moved from 35 degrees of flexion to 50 extension in task 1 , from 35 flexion to 68 degree extension in task 2 and from 80 flexion to 60 degrees extension in task 3 in normal condition. However, in supinator transfer model, wrist joint moved by 138.6, 120 and 138 degrees for task 1, 2 and 3, respectively. Moreover, the range of supination/pronation, ulnar/radial deviation increased follow tendon transfer. This is the same as the results of the study reported by Thatte et al, who confirmed that those with lesion at level C7-T1 and with wrist joint extensor paralysis have more motion of wrist joint division and rotation when wrist joint moved into extension [6].

Another important point which should be considered is the forces produced by supinator, extensors and flexors during doing the aforementioned tasks. The total force of extensors were 1249, 1506, and $1077 \mathrm{~N}$ for task 1,2 and 3 , respectively compared to 1279,1377 , and $766 \mathrm{~N}$ for flexor forces for task 1,2 and 3 , 
respectively, Table 2 . In contrast, the force of supinator was 57,145 , and $34 \mathrm{~N}$ for task 1,2 and 3 , respectively. Based on the pattern of activity of extensors and supinator in normal condition it can be defined that they have the same pattern in the motions, although the forces of this muscle cannot be compared with extensors. Therefore, it can be concluded that if supinator muscle strengthen by appropriate exercise, it can be a good choice for tendon transfer to restore the performance of wrist extensors. However, those patients may have some problems in doing heavy duty tasks which require more power of wrist extensors.

It should be emphasized that this is the first study which evaluated the efficiency of tendon transferred of supinator to wrist joint extensors. Moreover, the effects of tendon transferred of supinator to extensor muscles were evaluated in various daily activities (transverse reaching, vertical reaching and wrist motion). Last but not least the effect of this tendon transfer was tested on other upper limb joints. However, it should be noted that this is a case study and the results should be used with caution. Therefore, it is recommended that this study should be done on more number of the subjects in future studies.

\section{Conclusion}

The results of this study showed that use of supinator muscle tendon is a good option for paralysis of extensor muscles in those with BPI at C7-T1. The results showed that the range of motion of wrist joint was restored in various tests follow the tendon transfer of supinator. Due to limit number of the subjects participated in this study; the results of this study should be used with caution.

\section{Abbreviations}

BPI

Brachial plexus injuries

ASIS

Anterior superior iliac spine

MCP

Metacarpophalangeal joint

ROM

Range of motion

FDPI

Flexor digitorum profundus (index finger)

FDSL

Flexor digitorum superficialis (long finger)

FDSR

Flexor digitorum superficialis (ring finger)

FDSI

Flexor digitorum superficialis (index finger) 
FDPR

Flexor digitorum profundus (ring finger)

\section{Declarations}

Ethics approval and consent to participate: An ethical approval was obtained from Shiraz University of Medical sciences, Ethical Committee. Moreover each subject was asked to sign a consent form.

Consent for publication: All authors agreed to publish this paper.

Availability of data and materials: The data are available if requested.

Competing interests: None

Funding: None

Authors' contributions: all authors have the same contribution regarding the paper.

Acknowledgements: None

\section{References}

1. Sakellariou, V.I., et al., Treatment options for brachial plexus injuries. ISRN orthopedics, 2014. 2014: p. 314137-314137.

2. Bertelli, J.A. and M.F. Ghizoni, Results and current approach for Brachial Plexus reconstruction. Journal of brachial plexus and peripheral nerve injury, 2011. 6(1): p. 2-2.

3. Sinha, S., et al., Adult brachial plexus injuries: Surgical strategies and approaches. Neurol India, 2016. 64(2): p. 289-96.

4. Songcharoen, P., Management of brachial plexus injury in adults. Scand J Surg, 2008. 97(4): p. 317-23.

5. Jain, D.K.A., et al., An epidemiological study of traumatic brachial plexus injury patients treated at an Indian centre. Indian journal of plastic surgery : official publication of the Association of Plastic Surgeons of India, 2012. 45(3): p. 498-503.

6. Thatte, M.R., S. Babhulkar, and A. Hiremath, Brachial plexus injury in adults: Diagnosis and surgical treatment strategies. Annals of Indian Academy of Neurology, 2013. 16(1): p. 26-33.

7. Bentolila, V., et al., Complete traumatic brachial plexus palsy. Treatment and outcome after repair. J Bone Joint Surg Am, 1999. 81(1): p. 20-8. 
8. Khalifeh, J.M., et al., Cost-Effectiveness Analysis of Combined Dual Motor Nerve Transfers versus Alternative Surgical and Nonsurgical Management Strategies to Restore Shoulder Function Following Upper Brachial Plexus Injury. Neurosurgery, 2019. 84(2): p. 362-377.

9. Siqueira, M.G. and R.S. Martins, Surgical treatment of adult traumatic brachial plexus injuries: an overview. Arquivos de Neuro-Psiquiatria, 2011. 69: p. 528-535.

10. Belviso, I., et al., Brachial Plexus Injuries in Sport Medicine: Clinical Evaluation, Diagnostic Approaches, Treatment Options, and Rehabilitative Interventions. Journal of Functional Morphology and Kinesiology, 2020. 5(2): p. 22.

11. Hems, T., Nerve Transfers for Traumatic Brachial Plexus Injury: Advantages and Problems. Journal of Hand and Microsurgery, 2011. 3(1): p. 6-10.

12. Delp, S.L., et al., OpenSim: open-source software to create and analyze dynamic simulations of movement. IEEE Trans Biomed Eng, 2007. 54(11): p. 1940-50.

13. Seth, A., et al., Muscle Contributions to Upper-Extremity Movement and Work From a Musculoskeletal Model of the Human Shoulder. Frontiers in Neurorobotics, 2019. 13(90).

\section{Figures}

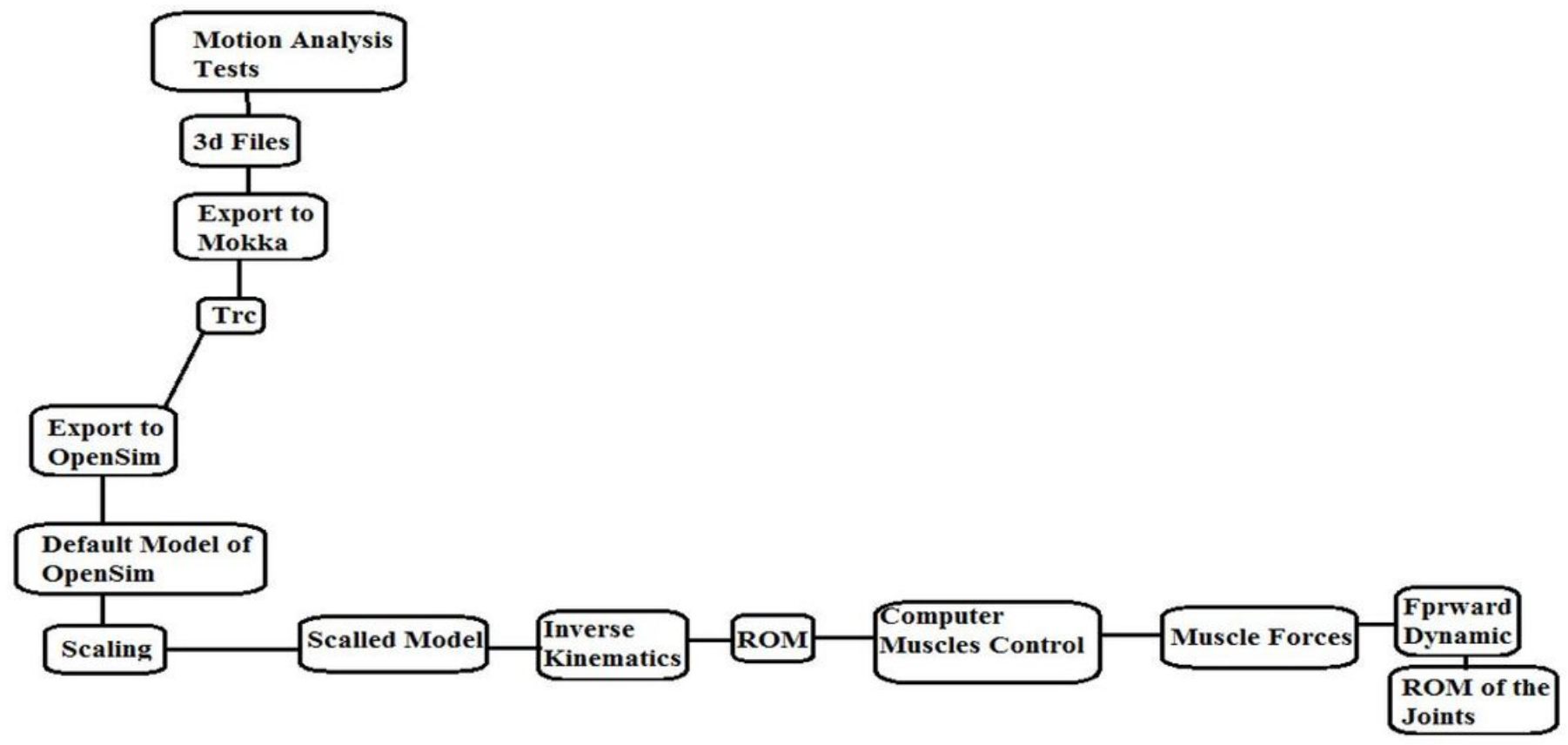

\section{Figure 1}

The procedure used in this study to determine muscles forces 


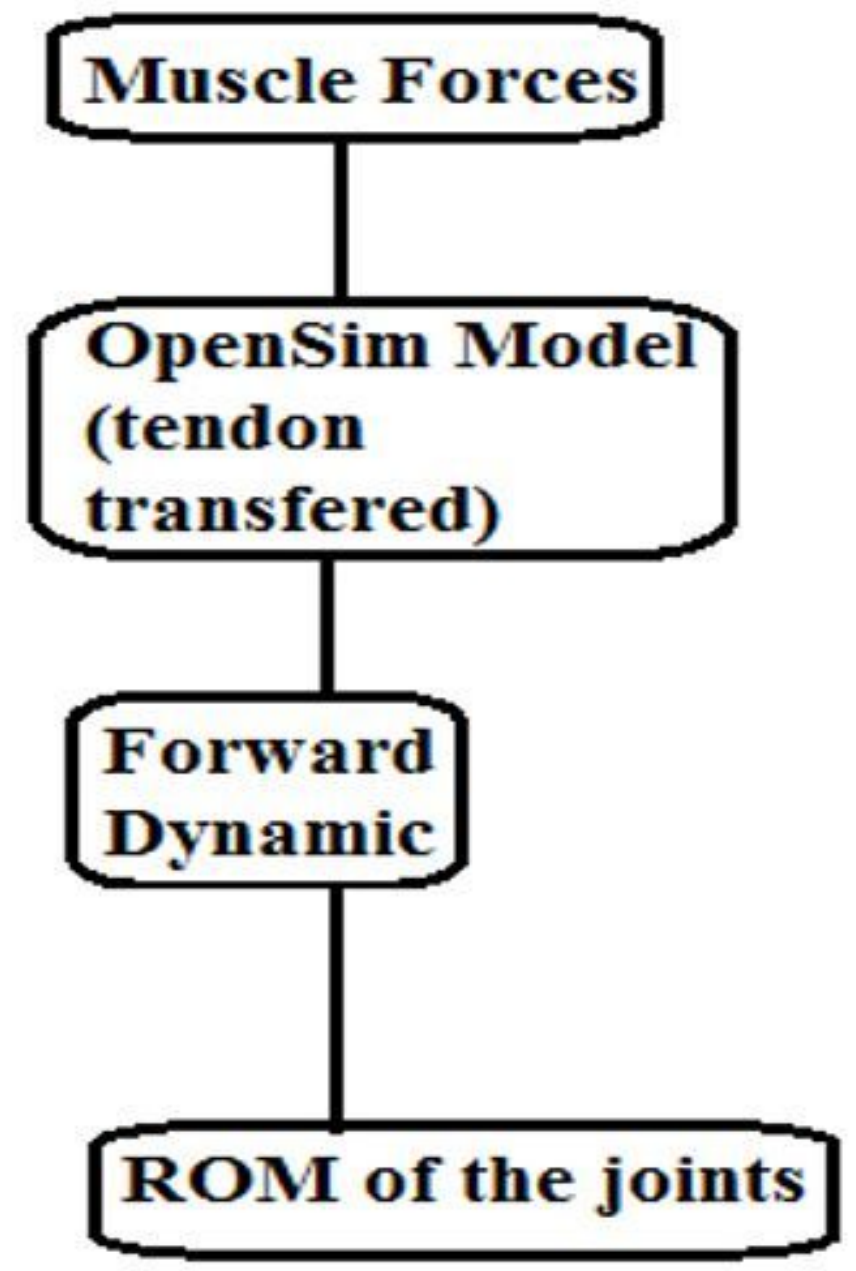

Figure 2

The procedure used to determine the efficiency of tendon transferred 


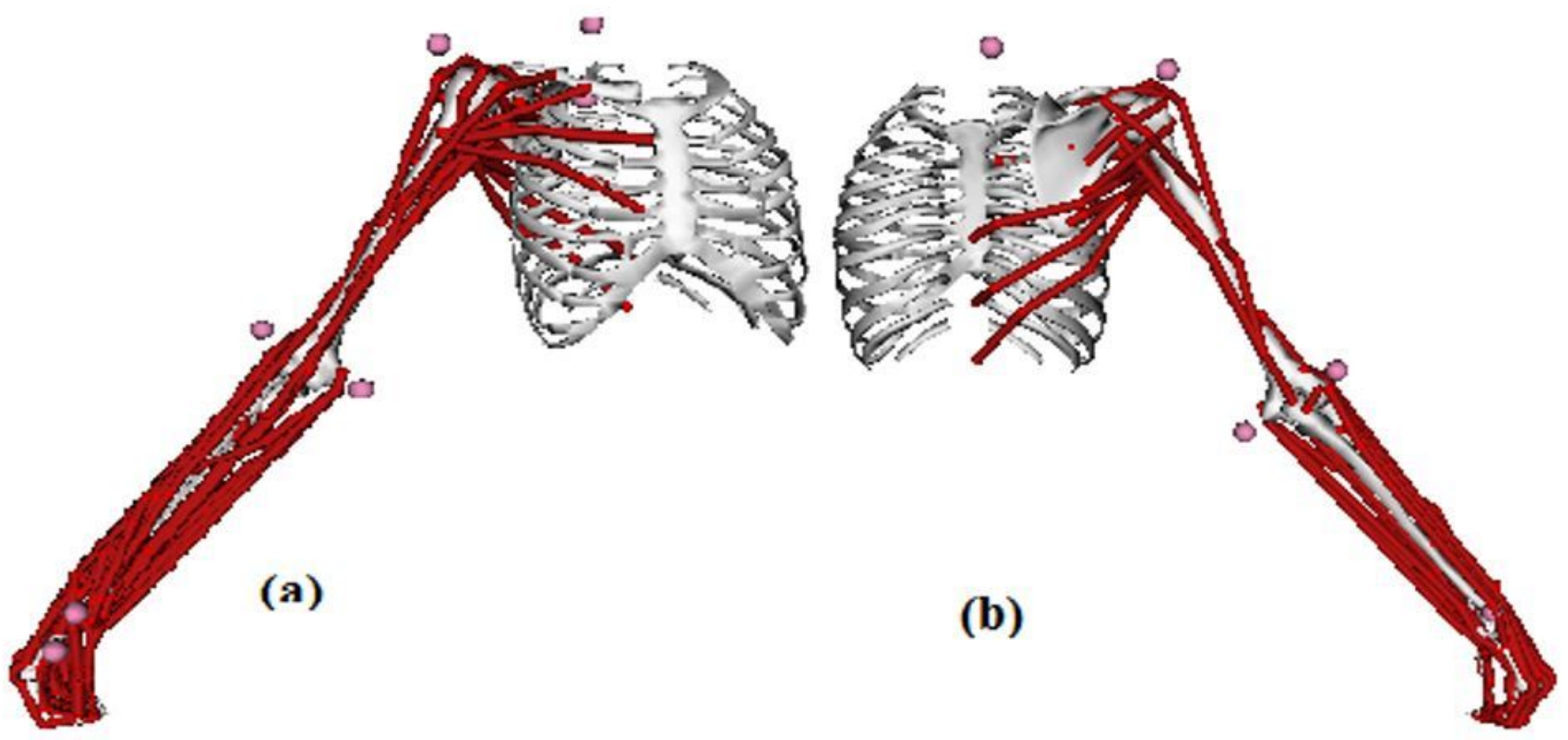

Figure 3

The OpenSim model used in this study, anterior view (a), posterior view (b) [13]

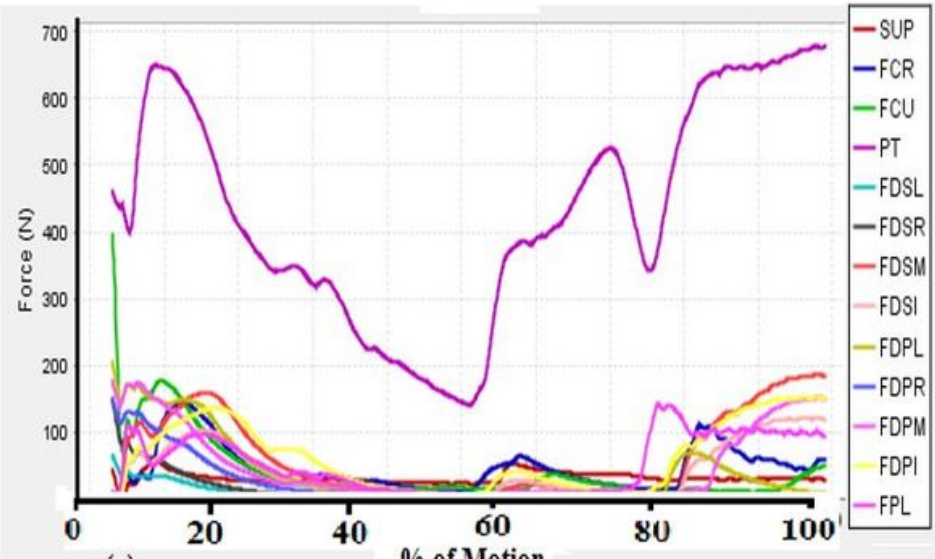

(a)

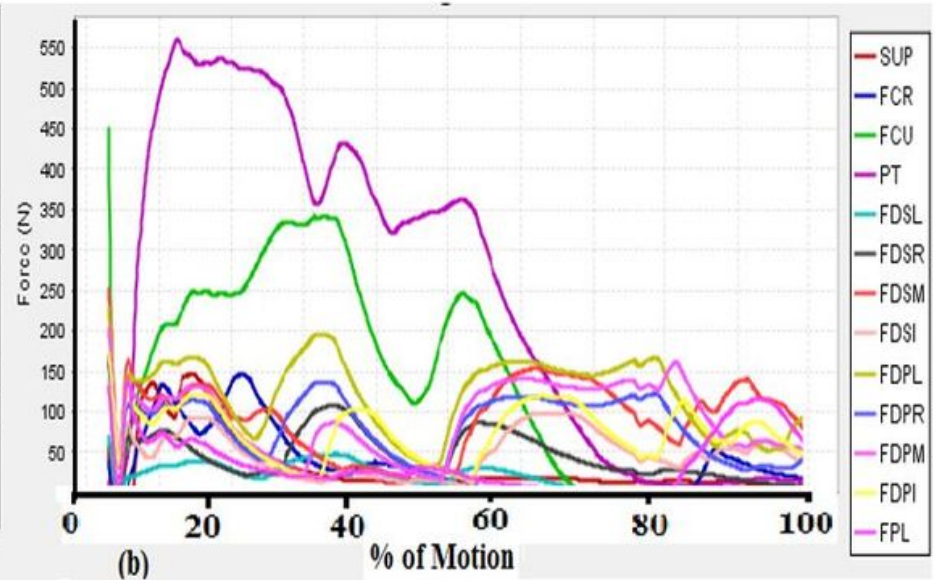

(b)

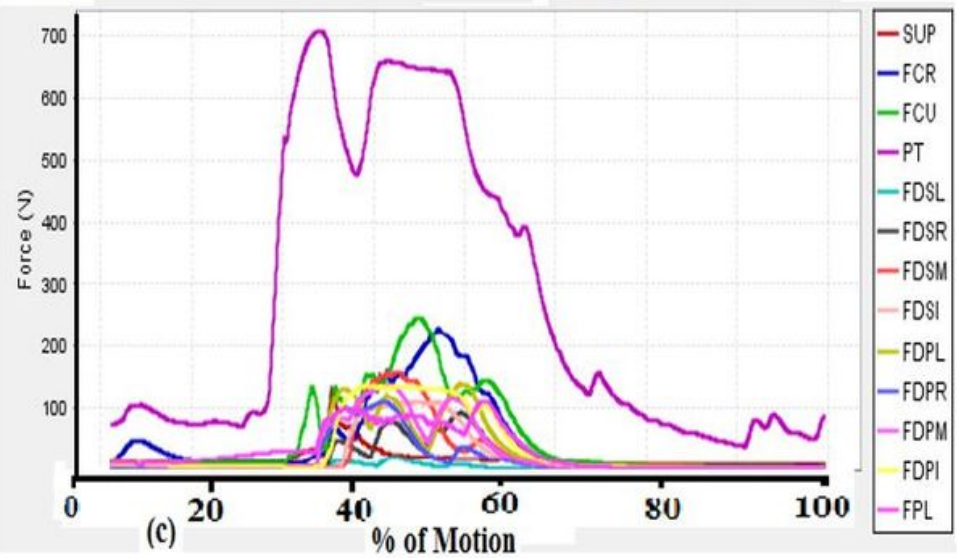

Figure 4 
The flexor muscles forces in task 1 (a), task 2 (b) and task 3 (c)
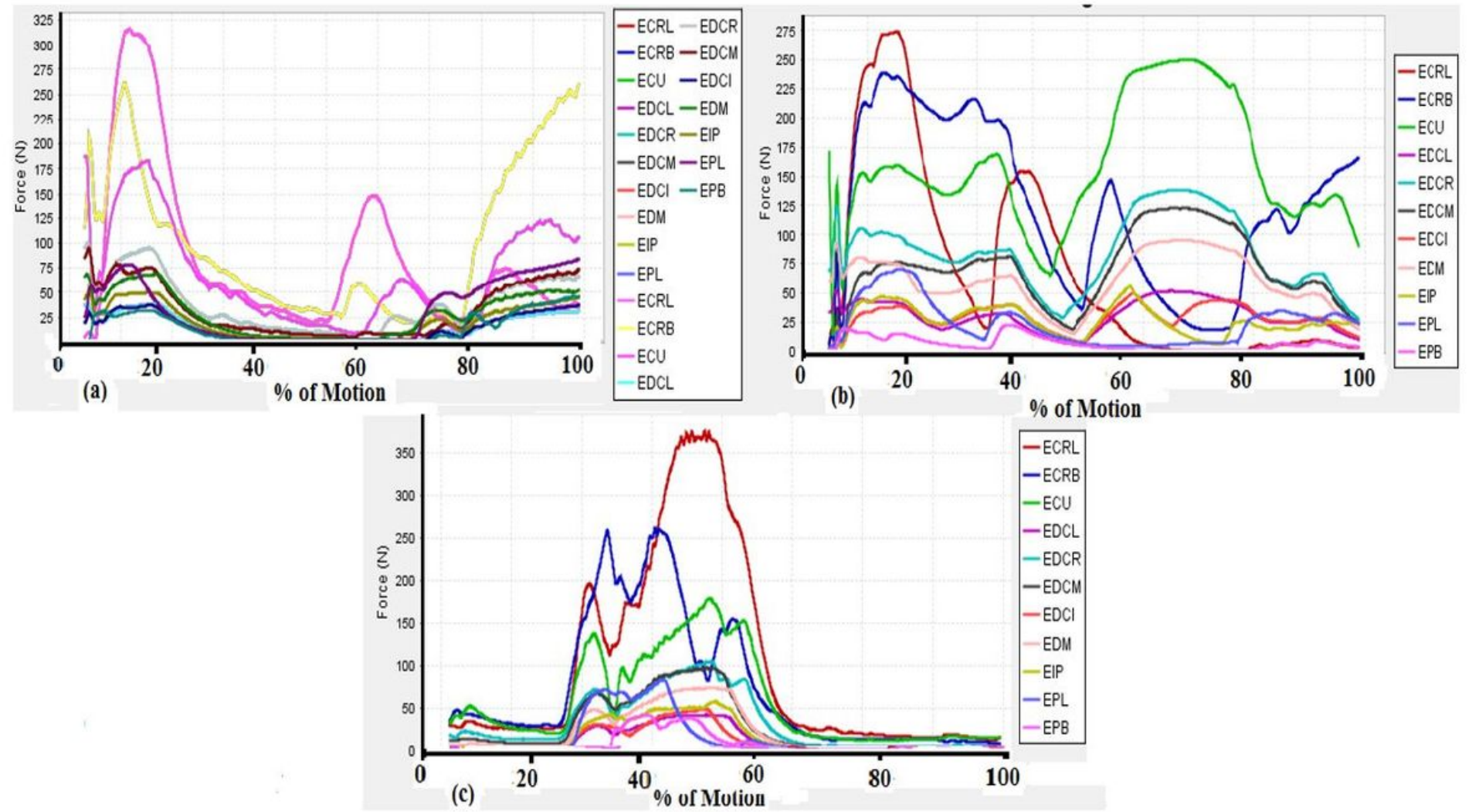

Figure 5

The forces of wrist extensors in task 1 (a), task 2 (b) and task 3 (c) 